\section{Evolving Great Universities in Small and Developing Countries}

\section{Pang Eng Fong and Linda Lim}

Pang Eng Fong is professor and director of the Wee Kim Wee Center at the Singapore Management University. Address: SMU, 469 Bukit Timah Rd., Singapore 259756, Singapore. E-mail: efpang@smu.edu.sg. Linda Lim is professor of corporate strategy and international business at the University of Michigan-Ann Arbor.E-mail: lylim@umich.edu.

$\mathrm{T}$ hese are challenging times for most universities, particularly public universities in developing countries. Budget constraints have compelled many to cut costs and programs. At the same time, changing expectations have thrust upon them new functions and roles. In East Asia, for example, public universities are expected to become more research oriented and link up with industry to enhance national economic competitiveness. To do so effectively, it is assumed they must aspire to "world-class" status and transform themselves into institutions that can compare favorably with the best in the West.

And the best in the West, it is widely accepted, are in the United States. U.S. universities are rightly renowned for their excellence and creativity. Their research has spawned ideas and products that have changed America and the world. Less well known is the fact that American colleges and universities are highly differentiated in size and orientation. Their diversity allows specialization and gives the system resilience. American universities, especially the research-oriented ones, however, are not without their critics. Detractors have indicted them for being too focused on research to the detriment of their teaching and public service obligations.

\section{The U.S. Model: Can It Be Emulated?}

The issue for universities in small or developing countries is whether the U.S. research university model is the right one to emulate, given that it has evolved in response to particular conditions and circumstances. A related question is whether lesswell-endowed countries are prepared to give their universities the resources over an extended period of time to enable them to compete for faculty with highly ranked U.S. universities.

In most other countries, national universities are state-funded comprehensive institutions. They don't have the scale and diversity of the United States or its ready access to a huge global pool of scholarly talent or to ample research funds from private as well as state sources.
In U.S. research universities, faculty research in most scholarly disciplines is evaluated in terms of publication in peer-reviewed academic journals. In this process, scholars in the same field review research paper submissions and decide whether they are worthy of publication in a particular journal. The most "highly ranked" journals tend to be those with the "purest" disciplinary focus.

Faculty whose interest is interdisciplinary and topical, or in place-specific or policy-oriented research, may have difficulty getting published in the top "internationally refereed" journals, thus defined. Research questions important in small and developing countries may not be of interest to the global discipline. And empirical data may not be available for sophisticated testing methodologies to be used.

Much depends on the subject area or discipline concerned. In pure science, there may be only a single global benchmark for research excellence. But in the humanities, social sciences, and many professional disciplines, global disciplinary benchmarks may not adequately capture local and regional specificities.

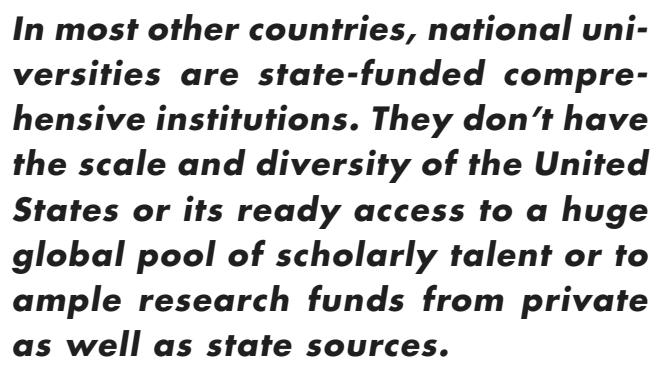

Intangibles

The "global standards" that are the hallmark of U.S. research universities may be adapted with some effort by other countries. More difficult to replicate are the intangibles such as the strong tradition of academic research and debate, protection for academic freedom, intellectual autonomy, faculty governance, and cultural tolerance and diversity.

These intangibles both encourage research and enable teaching pedagogies that interactively engage students and lecturers in critical thinking and open discussion. They attract people to join the profession despite monetary rewards often substantially below those in other sectors and professions. 


\section{The Importance of a Local Core}

In East Asia, as in other regions, universities are part of the national intellectual capital. While there is growing acceptance that foreign ideas and talent are necessary, it is also important to nurture a core of local faculty to give stability, local character, and cultural and intellectual rootedness to publicly supported universities.

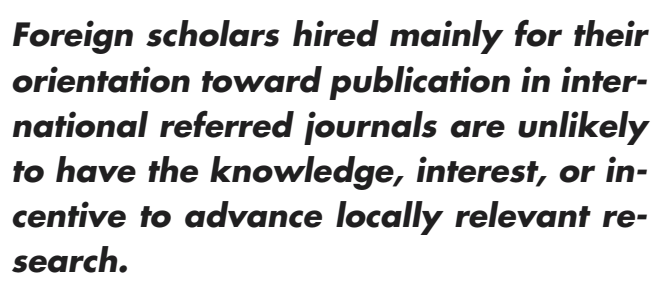

Evaluating faculty for promotion primarily on the basis of research publications in "top international (disciplinary) journals" may discourage place-specific applied research and publication. Such an approach deprives the nation of local knowledge and policyrelevant research. It also impoverishes the intellectual climate and cultural life, and stunts the development of local capabilities.

Foreign scholars hired mainly for their orientation toward publication in international refereed journals are unlikely to have the knowledge, interest, or incentive to advance locally relevant research. Some may use their positions to enhance their own global mobility. The best outcome may then be an institution no different from that of a local branch campus of a foreign research university. The country would be subsidizing research by foreigners for the world market. While it may add luster to the scholarly reputation of the foreigners, the research that is published may be quite irrelevant to the needs of the country that finances it.

In many Asian countries, a large number of local and foreign private educational institutions already exist to satisfy private demand for manpower training. National state institutions must play other roles that for-profit, especially foreign, institutions cannot-that is, research (especially place-specific research), and engagement with the community and with policymakers. This social and public role is vital to the development of civil society and the quality of life.

\section{Balancing Global Standards and Local Needs}

The challenge for small and developing countries aspiring to create world-class institutions of higher learning is to balance international academic standards with national needs and local identity and culture. For example, Singapore, which has three universities, can become the place in the world to learn about Southeast Asia in particular disciplines, by developing local channels for research publication by local and foreign scholars that become global standards in their particular scholarly niches.

As in Europe, Australia, and Japan, local institutions and scholars must play an active role in defining truly global-as distinct from derivative Americanstandards. At the same time, scholars who choose to conduct the kind of research favored by international refereed journals should continue to do so. Flexibility, sensitive adaptation, and time to adjust and mature are key to getting the best out of the U.S. research university model.

Fortunately, some of the best features of the model are neither costly nor time consuming to implement. They include: more nuanced admissions, student and faculty evaluation criteria-away from narrow reliance on grades, journal article counts, and numerical rankings and point scores; a shift from state direction to faculty control of academic life and institutions; and the vigorous contention of different ideas, perspectives, and people, in the context of "safe spaces" for all intellectual discourse. Countries that want world-class universities should also be prepared to make appropriate social and political adjustments.

\section{U.S. Higher Education: Long Reach Abroad with Tight Borders at Home}

\section{Thomas J. La Belle}

Thomas La Belle is executive director, International and Area Studies, at the University of California, Berkeley. Address: 360 Stephens Hall, U.C. Berkeley, Berkeley, CA 94720-2300. E-mail: tlabelle@uclink. berkeley.edu.

Tn the article, "Academic Colonialism in Action: 1 American Accreditation of Foreign Universities" (IHE, no. 32, summer 2003), Philip Altbach doesn't see problems in establishing U.S. institutions abroad, but he does see U.S. accreditation of institutions in other countries as a means of international colonialism and standardization. In response, this article argues, first, that it is unreasonable to disconnect the spread of U.S. higher education abroad from accreditation and, second, that the U.S. accreditation process also needs to be seen as a way of limiting foreign institutions from operating in this country. 